\title{
A REVIEW OF HEAT TRANSFER AND PRESSURE LOSS CHARACTERISTICS THROUGH CONVECTIVE COOLING METHOD FOR GAS TURBINE THERMAL MANAGEMENT
}

\author{
Divya Bihari \\ Department of Mechanical Engineering \\ Rajiv Gandhi Institute of Technology, Mumbai, India
}

\author{
Sanjay Bokade \\ Department of Mechanical Engineering \\ Rajiv Gandhi Institute of Technology, Mumbai, India
}

\begin{abstract}
Elevated temperatures in gas turbine operation exceeds the allowable temperature of the metal alloys used for turbine blades and combustor liners. Thus effective cooling strategies must be implement to ensure safe and efficient operation of gas turbines. Heat transfer enhancement can be achieved by increasing either the surface area or the heat transfer coefficient. Flow turbulence promoters such as ribs, dimples and protrusions induce a disturbance to the flow boundary layer. This lead to a regular separation and re-attachment of the near wall flow field, thus increasing the heat transfer coefficient. A number of geometric parameters like channel aspect ratio, rib-configurations, rib-orientation, blockage ratio, rib spacing, dimples and protrusions shape; depth and height have been investigated for cooling channels. The present study is aimed to review the investigation of these parameters on the heat transfer and pressure drop characteristics of cooling channels incorporated with turbulence promoters found in backside cooling of gas turbine combustor liner and internal cooling of turbine blades.
\end{abstract}

Keywords - Gas turbine, ribs, heat transfer enhancement, pressure loss, combustor liner, turbine blade cooling

\section{INTRODUCTION}

Gas turbines are designed to operate at increasingly higher turbine inlet temperature for improved efficiency and power output. It leads to the exposure of combustor liners and turbine blades to the temperatures higher than the melting point of their respective metal alloys. Therefore efficient cooling method must be applied to ensure the safe operation. Besides efficiency and power, modern gas turbine combustors are designed to reduce harmful emissions, such as Nitrogen oxides NOx, unburned hydrocarbon UHC, Carbon monoxide CO, Sulphur oxides SOx to minimize the negative impact on environment. Hence more air is used for premixing process and in reaction zone to maintain a low temperature.
Traditionally, gas turbine combustor liners are cooled by film cooling methods, due to its advantage of simplicity and high heat transfer coefficient. But it has some drawbacks that only part of compressor air can be used in combustion process which minimizes the overall efficiency. Also due to choking of combustion process in film cooling region, it results into undesired emission of pollutants. Another combustor wall cooling method is impingement cooling, where high heat transfer coefficient are realized. But it is accompanied with rise in pressure losses which will affect the cycle efficiency. Hence the application of impingement cooling should be limited to locations with high thermal loads.

So to provide a high amount of compressor air for the lean pre-mixed combustion process, enhanced backside cooling of combustor liner is suitable. The term "backside" refers to the liner surface side opposite to the combustion zone. In backside cooled wall, addition of geometrical features such as ribs, dimples and protrusions enhance the heat transfer rate by promoting turbulence and subsequently disturbing the boundary layer. This cooling method also helps to achieve regenerative cooling schemes, as all the liner cooling air is fed back to the burners. Therefore convective cooling plays a significant part in the internal cooling of combustor liner and turbine blades.

In this paper, an attempt has been made to review the analysis carried out by various researchers for heat transfer enhancement by using ribs, dimples and protrusions. It also review the effect of various parameters that affect the heat transfer and pressure drop characteristics in cooling passages typically found in Gas turbine blade and combustor liner.

\section{COOLING CHANNELS WITH RIBS}

\section{A. Ribs on two sides of the channel -}

Earlier studies on rib turbulators are mainly concerned with the application of internal cooling passages of turbine blades where ribs are located on both sides of the channel and the chosen configurations are generally transverse or angled 
Han et. al. (1985) [1] studied the effect of rib angle of attack $\left(90^{\circ}\right.$ to $60^{\circ}$ to $45^{\circ}$ to $\left.30^{\circ}\right)$ and rib pitch-to-height ratio (P/e) of 10 to 20 in a square duct. The tested Reynolds number vary from 7000 to 90,000 and the rib height-to-equivalent diameter ratio (e/D) was 0.063 . It was found that the thermal performance of the oblique angled ribs were higher than the transverse ribs. Han (1988) [2] also conducted experimental investigation to study the mutual effect of channel aspect ratio $(1 / 4,1 / 2,1,2$ and 4$)$ and rib pitch to height ratio (10 and 20) in rectangular channels with transverse ribs. The Reynolds number varied from 10,000 to 60,000 and the rib height-tohydraulic diameter ratios $\left(\mathrm{e} / \mathrm{D}_{\mathrm{h}}\right)$ were 0.047 and 0.078 . He concluded that the thermal performance decreases with increasing rib spacing or Reynolds number and increases with increasing rib height or channel aspect ratio, for a constant Reynolds number. Similar investigations were also carried out by Park et. al. (1992) [3]. They have investigated the combined effects of the channel aspect ratio, rib angle-ofattack, and flow Reynolds number in rectangular channels. The channel aspect ratio and the tested Reynolds number are the same as those of Han [2] while the corresponding rib angles-of-attack $(\alpha)$ were $90^{\circ}, 60^{\circ}, 45^{\circ}$ and $30^{\circ}$ respectively. The rib height-to-hydraulic diameter ratios $\left(\mathrm{e} / \mathrm{D}_{\mathrm{h}}\right)$ are 0.047 and 0.078 and the rib pitch-to-height ratio $(\mathrm{P} / \mathrm{e})$ is 10 . Best thermal performance were provided by the $60^{\circ}$ or $45^{\circ}$ angled ribs for the square channel; $45^{\circ}$ or $60^{\circ}$ angled ribs are recommended for the narrow aspect ratio channel; while the $30^{\circ}$ or $45^{\circ}$ angled ribs are better for wide aspect ratio channels.

Experimental investigations have discovered that the best thermal performance in a channel were provided by angled ribs as compared to the transverse ribs of the same geometry. The angled ribs generate secondary flows which are responsible for creating a span wise variation in heat transfer coefficient on the roughened wall, with high levels of heat transfer coefficient at one end of the rib and low levels at the other end. To double the area of high heat transfer coefficients, the angled rib is broken at the centre to form a Vshape rib and tests are conducted to investigate the resulting heat transfer coefficients and friction factors. [4]. Taslim et. al. (1994) [4] examined three different V-shaped square rib geometries, corresponding to blockage ratios $\left(\mathrm{e} / \mathrm{D}_{\mathrm{h}}\right)$ of 0.083 , $0.125,0.167$, with a fixed pitch-to-height ratio of 10 in a square channel. The tested Reynolds number ranges from 5000 to 30,000 . The results are compared with $90^{\circ}, 45^{\circ}$ and discrete angled ribs, which shows that the $\mathrm{V}$-shaped ribs with low blockage ratios gives the highest heat transfer enhancement and friction factors while the transverse ribs gives the lowest thermal performance.

Experimental investigations have also been conducted to show that one-sided ribbed wall channel have the best thermal hydraulic performance as compared to two-sided ribbed wall channel, owing to its benefit of decreased pressure losses. Chandra et. al. (2003) [5] investigated the effects of number of rib-roughened wall on the heat transfer and friction characteristics in a square channel with transverse ribs. The Reynolds number ranges from 10,000 to 80,000 . The pitch-toheight ratio $(\mathrm{P} / \mathrm{e})$ was 8 and the blockage ratio was 0.0625 . Maurer et. al. (2007) [6] investigated the performance of Vshaped ribs located on one side or on both sides of the test channel with an aspect ratio of 2:1. The Reynolds number ranges from 95,000 to 500,000 ; blockage ratios were 0.0625 and 0.02 and the rib pitch-to-height ratio was 10 . They concluded that the channel with two opposite ribbed walls show considerable increase in heat transfer enhancement over the one ribbed walls case, whereas the pressure loss was approximately doubled. At high Reynolds numbers smallscale ribs in a one-sided ribbed channel were shown to have the best thermal performance.

\section{$B$. Ribs on one side of the channel -}

Researchers have further led many comparative assessment between commonly used rib configurations located on one sided wall of the channel at high Reynolds number to simulate the conditions of cooling passages found in gas turbine blade as well as combustor liner.

Wright et. al. (2004) [7] conducted experimental study on angled, V-shaped and $\mathrm{W}$-shaped ribs of both continuous and discrete type in each case for rotating channels with an high aspect ratio of 4:1. The blockage ratio was 0.078 ; the rib pitchto-height ratio was 10 and the tested Reynolds number ranges from 10,000-40,000. The results concluded that W-shaped and discrete $\mathrm{W}$-shaped had the best thermal performance than $\mathrm{V}$-shaped and angled ribs, but it comes along with greatest frictional loss. Alkhamis et. al. (2011) [8] investigated the heat transfer and frictional loss of angled and V-shaped ribs with 450 angle of attack in a square duct at high Reynolds number ranging from 30,000 to 400,000 . The range of tested blockage ratio was 0.1 to 0.18 and the rib pitch-to-height ratio was 5 to 10. V-shaped ribs show a higher thermal performance than angled ribs. Similar comparative analysis was conducted by Maurer et. al. (2007) [9] experimentally and numerically to examine the thermal performance of $\mathrm{V}$-shaped and $\mathrm{W}$-shaped ribs in a rectangular channel with an aspect ratio of $2: 1$. The blockage ratio $\left(\mathrm{e} / \mathrm{D}_{\mathrm{h}}\right)$ was 0.02 ; the rib pitch-to-height ratios $(\mathrm{P} / \mathrm{e})$ were 5 and 10 and the tests were performed for Reynolds numbers between 80,000 to 500,000 . W-shaped ribs with a pitch-to-height ratio of 10 performed the best with slightly increased pressure loss than $\mathrm{V}$-shaped ribs. Kumar and Amano (2014) [10] investigated four different combination of $60^{\circ} \mathrm{V}$ and broken $60^{\circ} \mathrm{V}$-ribs for two pass square channels with a $180^{\circ}$ turn. Investigated Reynold's numbers were 16,000, 56,000 and 85,000. Area averaged data are calculated in order to compare the overall performance of the tested ribbed surface and to evaluate the degree of heat transfer enhancement induced by the rib. The overall performances for broken ribs are higher compared with the continuous ribs in two-pass cooling channels. Lamont et al. (2012) [11] examined the differences in heat transfer distributions on 
channel surfaces with smooth walls, $90^{\circ}$ rib and $\mathrm{W}$-shaped rib in rotating channel. The inlet coolant-to-wall density ratio was fixed at 0.08 , Reynolds number was 16,000, and Rotation number was 0.08 . The study shows that the $\mathrm{W}$-shaped ribs enhance heat transfer in all cases (stationary and rotating) approximately 1.75 times more than the $90^{\circ}$ ribs. The $\mathrm{W}$ shaped rib channel is least affected by rotation, which may be due to the complex nature of the secondary flow generated by the geometry. A higher pressure drop is associated with the $\mathrm{W}$-shaped ribs than the $90^{\circ}$ ribs, however, the overall thermalhydraulic performance of the $\mathrm{W}$-shaped ribs still exceeds that set by the $90^{\circ}$ ribs.

\section{$C$. Numerical studies on ribbed channel -}

In addition to experimental studies, several numerical investigations have also been carried out simultaneously to simulate the main flow structures of rectangular channels with one sided ribbed wall and to locate the existence of secondary flows generated by various rib configurations.

Ravi et al. (2016) [12] numerically investigated the heat transfer and friction characteristics of four different rib geometries- 450 angled, V-shaped, W-shaped and M-shaped ribs in a two-pass stationary channel. The aspect ratio of the cooling channel was 1:1 (square). The rib pitch-to-rib height ratio $(\mathrm{p} / \mathrm{e})$ and the rib-height-to-channel hydraulic diameter ratio $\left(\mathrm{e} / \mathrm{D}_{\mathrm{h}}\right)$ were 16 and 0.125 respectively. The Reynolds number was varied from 20,000 to70,000. For the computations, the Reynolds averaged Navier-Stokes (RANS) equations were solved with the commercial software ANSYS Fluent using the realizable version of $k-\varepsilon$ (RKE) model. The heat transfer enhancement provided by $\mathrm{V}$-shaped ribs was $7 \%$ higher than $45^{\circ}$ ribs, $28 \%$ higher than $\mathrm{W}$-shaped ribs and $35 \%$ higher than M-shaped ribs. However, the pressure penalty for V-shaped ribs was $19 \%$ higher than $45^{\circ}$ ribs, $24 \%$ higher than $\mathrm{W}$-shaped ribs and $28 \%$ higher than $\mathrm{M}$-shaped ribs. On comparing the overall thermal hydraulic performance, Vshaped and 450 ribs were observed to perform significantly better than $\mathrm{W}$-shaped and $\mathrm{M}$-shaped ribs.

Hagari et al. (2010) [13] investigated the heat transfer performance and pressure loss of the rib-roughened rectangular channels with relatively small $\mathrm{W}$-shaped ribs. Channel Reynold's number ranges from 40,000 to 550,000. The ribs were located on one side of the channel and the rib height-to-hydraulic diameter ratio (e/Dh) was 0.006-0.014, which simulate the combustor liner cooling configuration. Rib pitch-to-height ratio (P/e) was 10 . Heat transfer enhancements of about 3 were obtained over that of a flat plate at high Reynold's numbers for all cases. The slope of heat transfer coefficient becomes constant with increasing Reynold's number. Pressure loss measurements shows that the friction coefficients are constantly 3-4.5 times higher than those of a flat plate for a fully turbulent flow such as a combustor cooling passage. Numerical calculation predicted amount of heat released from the ribs contributes about $40 \%$ of the overall heat release even for low ribs.
Kunstmann et al. (2013) [14] investigated to assess the thermal performance of $\mathrm{W}$-shaped, $2 \mathrm{~W}$-shaped and $4 \mathrm{~W}$ shaped ribs in a rectangular channel. The aspect ratios $(\mathrm{W} / \mathrm{H})$ were $2: 1,4: 1$ and $8: 1$. The ribs were located on one channel wall. The rib height (e) was kept constant with a rib height-tohydraulic diameter ratio $\left(\mathrm{e} / \mathrm{D}_{\mathrm{h}}\right)$ of $0.02,0.03$ and 0.06 . The rib pitch-to-height ratio (P/e) was 10 . The Reynold's numbers investigated $(\operatorname{Re}>90,000)$ are typical for combustor liner cooling configurations of gas turbines. The numerical results show that the highest heat transfer enhancement is obtained by rib configuration with a rib section-to-channel height ratio $(\mathrm{Wr} / \mathrm{H})$ of $1: 1$. W-shaped ribs achieve the highest heat transfer enhancement levels in channel with an aspect ratio of $2: 1,2 \mathrm{~W}$ shaped ribs in channels with an aspect ratio of $4: 1$ and $4 \mathrm{~W}$ shaped ribs in channel with an aspect ratio of $8: 1$. Furthermore the pressure loss increases with increasing complexity of the rib geometry and blockage ratio.

Li et al. (2019) [15] presented an experimental and numerical study of turbulent flow heat transfer and pressure loss in channels with structured miniature ribs on one wall with the aim to improve the internal cooling performance of gas turbine blades and combustor liners. Miniature transverse, angled, Vshaped and $\mathrm{W}$-shaped ribs were investigated respectively in the study, and the aspect ratio of the channels is kept to be $6: 1$, and the rib pitch to height ratio was 10 and the rib height to mean hydraulic diameter ratio was 0.029 . The experiments were carried out at the Reynolds numbers ranging from 10,000 to 60,000 , and a low- Reynolds number k- $\varepsilon$ turbulence model was also adopted to simulate the turbulent flow and heat transfer in the channels. Both experimental and numerical results have shown that the shapes of miniature ribs have appreciable influences on the heat transfer and pressure loss performance in the channels. The experiments showed that the $\mathrm{W}$ ribs have the highest heat transfer and pressure loss performance in the channel, and the angled ribs have the lowest heat transfer and pressure loss performance in the channel. The W-ribbed channel shows respectively the globally averaged Nusselt numbers and overall Nusselt numbers of 2.2-2.6 and 2.9-3.3 times those of a smooth channel, and the friction factors of 2.5-3.7 times those of the smooth channel, which are higher than those of the $\mathrm{V}$-ribbed channel and the transverse ribbed channel. The miniature structured ribs show appreciable higher thermal performance than the conventional sized ribs.

\section{COOLING CHANNELS WITH DIMPLES AND PROTRUSIONS}

Dimples work on the principle of disturbing the laminar boundary layer and to create the turbulent boundary layer. It behave as a vortex generator to promote the turbulent mixing in the near-wall flow region, with lower pressure loss as compared to rib turbulators since they do not protrude into the flow.

Mahmood and Ligrani (2002) [16] studied the influence of dimples on flow structure and heat transfer for Reynolds 
numbers range of 600 to about 11000 and ratios of air inlet stagnation temperature to surface temperature ranging from 0.78 to 0.94 . Ratios of channel height to dimple print diameter of $0.20,0.25,0.50$, and 1.00 are tested. The ratio of dimple depth to dimple print diameter is 0.2 . Visualized flow smoke patterns show that the vortex pairs, which are periodically shed from the dimples, becomes stronger as non-dimensional channel height H/D decreases. Such behavior leads to local Nusselt number growths at these same locations, which also become larger as H/D decreases. Mhetras et al. (2014) [17] presented experimental results in a rectangular channel with an aspect ratio of 6 at very high Reynolds numbers up to 1.3 million. Three dimpled configurations including spherical and cylindrical dimples are studied on one wide wall of the channel. The presence of discrete ribs on the same wide wall is also investigated. Smaller spherical dimples gives best thermal performance among the three cases studied. Rao et al. (2015) [18] conducted a comparative experimental and numerical study to investigate the effects of dimple shapes on the heat transfer and flow friction of a turbulent flow over dimpled surfaces with different dimple shapes: spherical, teardrop, elliptical and inclined elliptical. The Reynolds number range of 8500-60000. The teardrop drop dimples show the highest heat transfer and the elliptical dimples have the lowest heat transfer than spherical dimples.

Another way of increasing the heat transfer rate of cooling channels is by applying protrusions to the channel wall. Surfaces with protrusions induce vortices to promote an enhanced mixing of the coolant, by which cooler air from the cold flow in transported towards the hot channel wall. Very few literatures are existed which provides detail study of heat transfer enhancement through protrusions.

Ligrani et al. (2002) [19] compared the flow structure characteristics for a channel with a dimpled surface on one wall, both with and without protrusions (with the same shapes as the dimples) on the opposite wall in a channel of aspect ratio 16 , ratio of channel height to dimple print diameter is 0.5 , and Reynolds number based on channel height range was 380 to 30,000 . Instantaneous flow visualization images and surveys of time-averaged flow structure show that the protrusions induces vortical, secondary flow structures and flow mixing. As a result, local friction factors and local Nusselt numbers are augmented compared to a channel with no protrusions on the top wall.

Maurer et al. (2008) [20] had done a comparative study to determine the heat transfer performance of $\mathrm{W}$-shaped, WWshaped ribs and uniformly distributed hemispheres with four different roughness spacings. The overall conclusion was hemisphere protrusions can be used where friction factor is the limiting parameter. If heat transfer performance is the desired design parameter, $\mathrm{W}$-shaped ribs represent the most efficient choice.

\section{COOLING CHANNELS WITH COMPOUND CONFIGURATIONS}

For higher heat transfer enhancement, two or more methods can be applied simultaneously. Combining rib turbulators and dimple or rib turbulators and protrusions achieve higher thermal hydraulic performance in comparison to rib-alone, dimple-alone or protrusion-alone. Some researchers have attempted compound cooling technique to achieve heat transfer enhancement.

Kunstmann et al. (2010) [21] conducted an investigation to assess the thermal performance of $90^{\circ}$ ribs, low and high $\mathrm{W}$ shaped ribs, and combinations of low $\mathrm{W}$-shaped ribs with high $\mathrm{W}$-shaped ribs and with dimples in a rectangular channel with an aspect ratio $(\mathrm{W} / \mathrm{H})$ of $2: 1$. The blockage ratios $\left(\mathrm{e} / \mathrm{D}_{\mathrm{h}}\right)$ were 0.02 with the $90^{\circ}$ ribs and the low $\mathrm{W}$-shaped ribs and 0.06 with high $\mathrm{W}$-shaped ribs. The rib pitch-to-height ratio (P/e) were 10 and 20 . The channel height-to-dimple diameter (H/D) was 16.67 ; the dimple depth-to-dimple diameter $(\delta / \mathrm{D})$ was 0.3 . The ribs and the dimples were located on one channel wall (side W). The Reynolds numbers investigated $(\operatorname{Re}>$ 100k) are typical for combustor liner cooling configurations in gas turbines. The different configurations were investigated numerically to visualize the flow pattern in the channel and to support the understanding of the experimental data. The best thermal performance is achieved by regularly spaced lower $\mathrm{W}$-shaped ribs and by a compound roughness of regularly spaced W-shaped ribs and dimples at Re below and above 300,000 , respectively.

Singh and Ekkad (2017) [22] investigated the heat transfer $\&$ pressure drop characteristics of a two-pass channel $(\mathrm{AR}=1)$ featuring ribs alone, dimple alone and combination of ribs and dimples. The ribs are V-shaped with rib-height-to-hydraulic diameter ratio of 0.125 and rib-pitch-to-rib height ratio of 16 . Dimples are cylindrical in shape and have a depth-to-print diameter ratio of 0.3 . The experiments were carried out for a wide range of Reynolds number $(19,500-69,000)$ to cover the full spectrum typically found in both land-based and airbreathing engines. It has been observed that combination of ribs and dimples resulted in higher heat transfer augmentation as well as higher thermal hydraulic performance as compared to ribs alone $\&$ dimple alone.

Jang et al. (2017) [23] studied heat transfer augmentation of a ribbed channel using dimple and protrusions of various shapes. The tested Reynolds numbers based on the channel hydraulic diameter are 30,000, 50,000 and 70,000. The channel aspect ratio and hydraulic diameter were 2 and $0.0533 \mathrm{~m}$. Both the height and thickness of ribs are $5 \mathrm{~mm}$ and the rib installation angle was $60^{\circ}$. Both the semi-spherical and oval protrusions were tested for the rib-protrusion compound cases. The case with lower protrusions showed a higher heat transfer augmentation and thermal performance factor than the case with higher semi-spherical protrusions. The dimples were 


\section{International Journal of Engineering Applied Sciences and Technology, 2019 \\ Vol. 4, Issue 4, ISSN No. 2455-2143, Pages 49-54 \\ Published Online August 2019 in IJEAST (http://www.ijeast.com)}

more effective in heat transfer augmentation in the ribbed channel while the pressure loss was higher than that for the protrusion cases.

\section{CONCLUSION}

From the present review it can be concluded that a lot of work has been carried out to increase the heat transfer coefficient and to reduce the pressure loss in cooling channels for gas turbine thermal management. Geometric parameters like channel aspect ratio, rib configurations, rib orientation, rib pitch-to-height ratio, dimple shape and depth; protrusion height affect the heat transfer rate and pressure drop characteristics. Following findings are observed from the literatures reviewed.

1. The dimples were more effective in heat transfer augmentation in the ribbed channel while the pressure loss is higher than that for the protrusion cases. Compared to spherical dimples, the teardrop dimples have the higher heat transfer performance with increased pressure loss as the Reynolds number increases.

2. Heat transfer on ribs accounts a large amount of heat flux which indicates that the rib contributes significantly to the heat transfer enhancement for cooling passage.

3. Secondary flow induced by ribs has significant influence on the heat transfer of the cooling channel. The secondary flow initiates at the upstream apexes, whirls along these ribs and then gathers in downstream corners. This strengthens the flow mixing between the air near wall and the mainstream, causing the heat transfer enhancement.

4. There is a significant increase in the wetted surface area in ribbed channel. Hence the heat transfer by ribs is not only through strong turbulence and mixing of flow structures but also enlarging the wetted surface area.

5. The secondary flow generated at the central apexes pointing upstream by $\mathrm{V}$-shaped and $\mathrm{W}$-shaped ribs have very strong characteristics and plays a significant role in heat transfer enhancement as it strengthens the flow mixing among the mainstream and near wall flow field. Hence the performance of $\mathrm{V}$-shaped and $\mathrm{W}$-shaped ribs are better than the angled and transverse ribs.

6. With same Reynolds number and rib pitch-to-height ratio, the $\mathrm{W}$-shaped ribs give the best thermal performance but the $\mathrm{V}$-shaped ribs give the best hydraulic performance with decreased pressure losses.

7. There are one pair of counter vortices and two pairs of counter vortices for V-ribs and W-ribs respectively, generated by the apexes pointing upstream which causes high level of flow mixing lead to the enhanced heat transfer performance.

The heat transfer enhancement in ribbed channel are also mainly due to the secondary flow generated by the rib corners. The secondary flow generated by $\mathrm{V}$-shaped and $\mathrm{W}$-shaped ribs have very strong characteristics as the number of rib apexes plays a significant role in heat transfer enhancement as it strengthens the flow mixing among the mainstream and near wall flow field. However the investigation of thermalhydraulic performance on various configurations of $\mathrm{W}$-shaped ribs i.e. $2 \mathrm{~W}$ and $4 \mathrm{~W}$ in the cooling channels have been less reported. Also the compound configuration of discrete ribdimple and discrete rib-protrusion for cooling channel have not been explored much and could be the focus of new research.

\section{REFERENCE}

[1] Han J. C., Park J. S., Lei C. K. (1985). Heat Transfer Enhancement in Channels With Turbulence Promoters, Transactions of the ASME, Vol. 107, pp 628-635

[2] Han J. C. (1988). Heat Transfer and Friction Characteristics in Rectangular Channels With Rib Turbulators, ASME Journal of Heat Transfer, Vol. 110, pp 321-328.

[3] Park J. S., Han J. C., Huang Y., Ou S., Boyle R. J. (1992). Heat transfer performance comparisons of five different rectangular channels with parallel angled ribs, International Journal of Heat and Mass Transfer, Vol.35 No.11, pp 2891-2903.

[4] Taslim M. E., Li T., Kercher D. M. (1994). Experimental Heat Transfer and Friction in Channels Roughened with Angled, V-shaped and Discrete Ribs on two opposite walls, Transactions of the ASME.

[5] Chandra P. R., Alexander C. R., Han J. C., (2002). Heat transfer and friction behaviors in rectangular channels with varying number of ribbed walls, International Journal of Heat and Mass Transfer, pp 481-495.

[6] Maurer M., Wolfersdorf J. V., Gritsch M. (2007). An Experimental and Numerical Study of Heat Transfer and Pressure Loss in a Rectangular Channel With V-Shaped Ribs, ASME Journal of Turbomachinery, 129, pp. 800808.

[7] Wright L. M., Fu W. L., Han J. C. (2004). Thermal Performance of Angled, V-Shaped, and W-Shaped Rib Turbulators in Rotating Rectangular Cooling Channels (AR=4:1), ASME Journal of Turbomachinery, 126, pp. 604-614.

[8] Alkhamis N. Y., Rallabandi A. P., Han J. C. (2011). Heat Transfer and Pressure Drop Correlations for Square Channels With V-Shaped Ribs at High Reynolds Numbers, ASME Journal of Heat Transfer, 133/1119011-8.

[9] Maurer M., Wolfersdorf J. V., Gritsch M. (2007). An Experimental and numerical study of heat transfer and pressure losses of V-and W-shaped ribs at high Reynolds numbers, Proceedings of ASME Turbo Expo: Power for Land, Sea and Air, Montreal, Canada.

[10] Kumar S., Amano R. S. (2014). Experimental investigation of heat transfer and flow using $\mathrm{V}$ and broken 
$\mathrm{V}$ ribs within gas turbine blade cooling passage, Heat Mass Transfer, Springer.

[11] Lamont J. A., Ekkad S. V., Alvin M. A. (2012). Detailed heat transfer measurements inside rotating ribbed channels using the transient liquid crystal technique, ASME Journal of Thermal Science and Engineering Applications, Vol. 4 / 011002-1-11.

[12] Ravi B. V., Singh P., Ekkad S. V. (2016). Numerical investigation of turbulent flow and heat transfer in twopass ribbed channels, International Journal of Thermal Sciences 112, pp 31-43, Elsevier.

[13] Hagari T., Ishida K., Oda T., Douura Y., Kinoshita Y. (2011). Heat Transfer and Pressure Losses of W-Shaped Small Ribs at High Reynolds Numbers for Combustor Liner, ASME Journal of Engineering for Gas Turbines and Power, 133/ 091901, pp 1-9.

[14] Kunstmann S., Wolfersdorf J. V., Ruedel U. (2013). Heat Transfer and Pressure Loss in Rectangular One-SideRibbed Channels With Different Aspect Ratios, ASME Journal of Turbomachinery, 135/031004, pp 1-9.

[15] Li Y., Rao Y., Wang D., Zhang P., Wu X. (2018). Heat transfer and pressure loss of turbulent flow in channels with miniature structured ribs on one wall, International Journal of Heat and Mass Transfer 131, pp 584-593, Elsevier.

[16] Mahmood G.I., Ligrani P.M. (2002). Heat transfer in a dimpled channel: combined influences of aspect ratio, temperature ratio, Reynolds number, and flow structure, International Journal of Heat and Mass Transfer, 45, pp 2011-2020.

[17] Mhetras S., Han J. C., Huth M. (2014). Heat Transfer and Pressure Loss Measurements in a Turbulated High Aspect Ratio Channel With Large Reynolds Number Flows, ASME Journal of Thermal Science and Engineering Applications, 6/ 041001, pp 1-11

[18] Rao Y., Li B., Feng Y., Weigand B. (2015). Experimental and Numerical Study of Heat Transfer and Flow Friction in Channels With Dimples of Different Shapes, ASME Journal of Heat Transfer, 137 / 031901, pp 1-10.

[19] Ligrani P. M., Mahmood G. I., Harrison J. L., Clayton C. M., Nelson D. L. (2001). Flow structure and local Nusselt number variations in a channel with dimples and protrusions on opposite walls, International journal of Heat and Mass Transfer 44, pp 4413 - 4425.

[20] Maurer M., Ruedel U., Gritsch M., Wolfersdorf J. V. (2008). Experimental study of advanced convective cooling techniques for combustor liners, Proceedings of ASME Turbo Expo: Power for Land, Sea and Air, Berlin, Germany.

[21] Kunstmann S., Wolfersdorf J. V., Ruedel U. (2010). Heat transfer and pressure drop in combustor cooling channels with combination of geometrical elements, Proceedings of
ASME Turbo Expo: Power for Land, Sea and Air, Glasgow, UK.

[22] Singh P., Ekkad S. (2017). Experimental study of heat transfer augmentation in a two pass channel featuring $\mathrm{V}$ shaped ribs and cylindrical dimples, Applied Thermal Engineering, 116, pp 205-216, Elsevier.

[23] Jang H. N., Park J. S., Kwak J. S. (2017). Experimental study on heat transfer characteristics in a ribbed channel with dimples, semi-spherical protrusions, or oval protrusions, Applied Thermal Engineering, Elsevier.

[24] Schulz A. (2001). Combustor liner cooling technology in scope of reduced pollutant formation and rising thermal efficiencies, Annals new York academy of sciences, pp 135-146.

[25] Bunker R.S. (2008). Innovative gas turbine cooling techniques, WIT Press, Vol 42, pp 199-229. 